\title{
ULTRA WIDEBAND SOUNDING SIGNALS IN HYDROACOUSTIC SYSTEMS
}

\author{
Anatoly V. Sknarya, Anatoly A. Razin, Sergey A. Toshchov, Aleksey I. Demidov \\ JSC V.V. Tikhomirov Scientific Research Institute of Instrument Design, https:/ / niip.ru \\ Zhukovsky 140180, Moscow Region, Russian Federation \\ sknarya.a@otd301.niip.ru,razin.a@nio3.niip.ru, toshovserdey@mail.ru, aleksii-ad@yandex.ru
}

Abstract. Results of comparison of full-scale tests of active sonar systems - sonars with narrowband and ultra wideband (UWB) sounding signals with linear frequency modulation of pulses are presented. It is shown that the use of UWB signals with a large base allows to resolve multiple echo-signals from the target in the time domain, and a wide operating frequency band allows for an efficient spectral analysis of the received signal. The principal difference between the mutualcorrelation functions of the echo signals for the cases of narrowband and UWB sounding is shown. Spectral portraits of targets, various in form and material, obtained with the use of UWB signals are presented. Sounding the targets with a UWB signal showed a higher degree of contrast and clarity of the acoustic images in comparison with the use of the narrowband signal. Thus, it is shown that UWB signals can be used to solve problems of recognition and classification of underwater objects in difficult conditions

Keywords: ultra-wideband signals, sonar, targets classification

UDC 621.396.96

Bibliography - 9 references

Received - 24.08.2018

RENSIT, 2018, 10(2):209-212

DOI: $10.17725 /$ rensit.2018.10.209

\section{Content}

1. Introduction (209)

2. Material and methods (209)

3. Results (210)

4. Discussion (211)

5. Conclusion (211)

References (212)

\section{INTRODUCTION}

Modern requirements to the technical characteristics of hydroacoustic systems, which solve the problem of classification of various underwater objects, force the developers to search for new methods and signals for solving this problem.

The first sonars used as a probing signal a short tone. At the turn of the 1970s and 1980s, when the question of improving the sonar parameters was particularly acute, there was a revolutionary transition to the use of complex narrow-band signals as probing signals, for example, chirp signals. It should be noted that such a transition in radar occurred much earlier - in the late 50-ies of the twentieth century. The use of complex narrow-band probing signals in active hydroacoustic systems (HAS) contributed to the development of sonar with high technical characteristics, which allowed solving most problems for several decades.

However, at the present time there is a need for further improvement of active HAS. The use of narrow-band sounding signals allowed, with the preservation of high resolution in range, to increase the range of action of the sonar by 2-3 times [1]. However, in this case, further increase in the range of the SAS operation due to the use of narrowband complex signals to ensure high resolution in range is not possible because of the large attenuation of acoustic oscillations at high frequencies [2]. In addition, the bulk of the work is currently carried out in the coastal zone in shallow water. Under these conditions, such parameters of sonar as noise immunity and the possibility of working under multipath conditions are put on the first place.

\section{MATERIALS AND METHODS}

At the present stage of the development of sonar, effective detection of objects in the water column is possible only with the use of active sonars. 
The emergence of new technologies that have significantly reduced their own target noise and their sizes make it very difficult to detect targets in the passive location mode. An example is the emergence of autonomous uninhabited underwater vehicles.

The problem is not only the detection of targets at the required range in difficult conditions, but also their classification. When narrow-band probing signals are used, classification of targets is performed either from an acoustic image (for example, targets lying on the bottom surface) or from trajectory measurements for moving targets. In the first case, it is necessary to obtain a high-quality contrast acoustic image with a high resolution on the background of the underlying surface, which is quite difficult and not always solvable, especially for forward-looking systems.

One of the ways to solve the above-mentioned problems is to use ultra-wideband signals (UWBS) as probing signals in active HAS [3]. Similar works have been actively conducted abroad in recent years $[4,5]$.

The use of a low-frequency range of operating frequencies with a significantly wider bandwidth relative to narrowband complex signals makes it possible to solve the "distance-resolution" problem more effectively [6]. At the same time, the use of a wider frequency band of the probing signal increases the noise immunity of active SAS and allows operation under multipath conditions.

\section{RESULTS}

In the V.V. Tikhomirov NIIP for several years, systematic work has been carried out to investigate the use of UWBS in sonar. Theoretical research refers to the development of algorithms for the formation of UWB, their processing and the influence on their properties of the propagation medium. At the level of engineering solutions, the development of reception, radiation and the whole sonar in general is being developed. In recent years, several sonar models with UWB sounding signals have been developed and their full-scale tests were carried out. The results thus obtained confirmed not only the possibility, but also the prospects of using these signals in active sonars, including for the solution of the "distance-resolution" problem [7, 8].

As an example, in Fig. 1 and Fig. 2 shows the acoustic images of the same bottom section

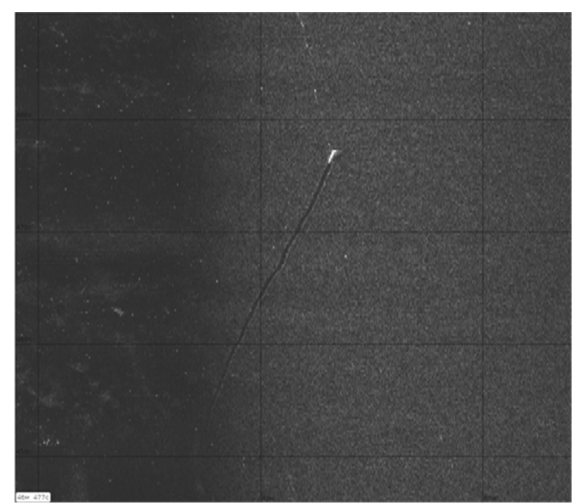

Fig. 1. Acoustic image of a cylindrical object lying on the surface of the bottom, obtained with the help of Nesan SSVE-250.

obtained during joint tests at the Ladoga of sonar side view (SSV) of the Neman series - SSVE250 and the SSV model with the UWB sounding signal. In sonars, the LFM (linear frequency modulation) signal was used as the probing signal with the following parameters: Neman SSV - 6 ms signal duration, $24 \mathrm{kHz}$ frequency deviation, lower frequency - $236 \mathrm{kHz}$; a SSV layout with a UWBS - a signal duration of $2 \mathrm{~ms}$, a deviation of the frequency of $78 \mathrm{kHz}$, a lower frequency of $78 \mathrm{kHz}$. During the experiment, the receiving and transmitting antennas of the sonars were located on one bar that was attached to the ship's side. The sonar operation was carried out simultaneously. In this case, the carrier vessel moved from the left from the bottom to the top (see Fig. 1, and Fig. 2). A metal cylinder was used as the target, to which was attached a metal cable $11 \mathrm{~mm}$ in diameter, which ended in a buoy.

An essential advantage of the UWB sounding signal is the possibility of using a high information value of the echo signal when solving the task of classification of targets. When processing UWB signals, the formation of temporal and spectral

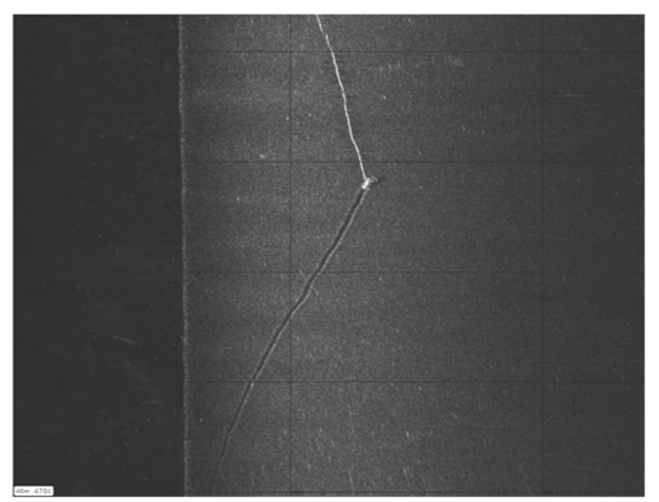

Fig. 2. Acoustic image of a cylindrical object lying on the surface of the bottom, obtained with the help of a SSV layout with a $U W B$. 


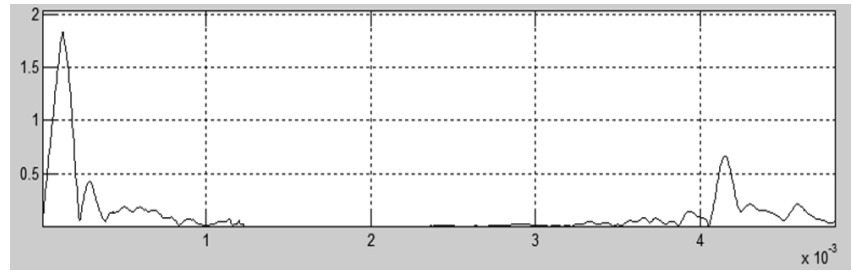

Fig. 3. CCF echo signal reflected from a solid steel sphere with a diameter of $100 \mathrm{~mm}$ for the case of a narrow-band chirp signal.

portraits of the target is possible. The use of UWB signals with a large base allows to resolve multiple echoes from the target in the time domain, and a wide operating frequency band allows for an efficient spectral analysis of the received signal.

In Fig. 3 and Fig. 4 shows the cross-correlation functions (CCF) of the echo signal reflected from a solid steel sphere with a diameter of $100 \mathrm{~mm}$ for the case of a narrow-band chirp signal (115$125 \mathrm{kHz}$ ) and a CCF of echo signal also reflected from the same sphere for a LFM UWB signal (78 $-142 \mathrm{kHz}$ ). The abscissa is the time in ms. The scale along the abscissa axis for all graphs is the same. At the beginning of the abscissa axis, the CCF of the radiated signals is shown.

Fig. 3 and 4 show the fundamental difference between the CCF of the narrowband echo signal and the UWB of the UWB echo signal: in Fig. 4 CCF of echo signal from the target has a characteristic extended structure of several maxima, in Fig. 3 - CCF of narrowband signal is an envelope of a smooth contour with one maximum.

Table 1 presents the characteristics of some targets used during one of the field experiments.

In Table 2, photographs of targets, their spectral portraits (A) and CCF (B) are presented. The $X$ axis in the graphs $\mathrm{A}$ is the frequency (in counts) and the $Y$ axis is the normalized spectral density. On the $X$-axis, the time (in $s$ ) is plotted on the graphs of $\mathrm{B}$, and the amplitude of the CCF (in the samples) along the $Y$ axis. The data were obtained using the LFM UWB signal with the parameters indicated above.

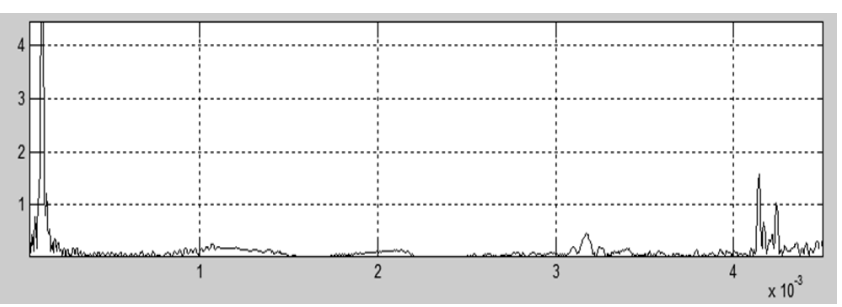

Fig. 4. CCF echo signal reflected from a solid steel sphere with a diameter of $100 \mathrm{~mm}$ for the case of a LFM UWB signal.
Table 1.

Set of targets and their main characteristics

\begin{tabular}{|c|l|l|l|l|}
\hline № & Form & \multicolumn{1}{|c|}{$\begin{array}{c}\text { Overall } \\
\text { dimensions, } \mathrm{mm}\end{array}$} & Material & Type \\
\hline 1 & sphere & $\varnothing 105$ & steel & solid \\
\hline 2 & sphere & $\varnothing 100$ & foam plastic & solid \\
\hline 3 & cylinder & $\varnothing 57, \ell=255$ & steel & solid \\
\hline 4 & tube & $\varnothing 110, \ell=500$ & PVC & hollow \\
\hline
\end{tabular}

\section{DISCUSSION}

From the comparison of the acoustic images shown in Figs 1 and 2, it follows that the acoustic image obtained with the help of the SSV model with the UWB probe signal differs significantly better contrast and clarity. Especially it should be noted that in Fig. 2 clearly seen the cable, and in Fig. 1 cable was not found.

The graphs given in Table 2 show the difference between CCF and spectral portraits for different purposes in form and made from different materials, which can be used to classify targets, including in automatic mode without operator involvement. As for the nature of the formation of a temporary portrait, it can be quite complicated. The temporal portrait can be formed both due to the spatial extent of the target, and, for example, by excitation of various types of waves in the target, which leads to

\section{Portraits of targets}

Table 2

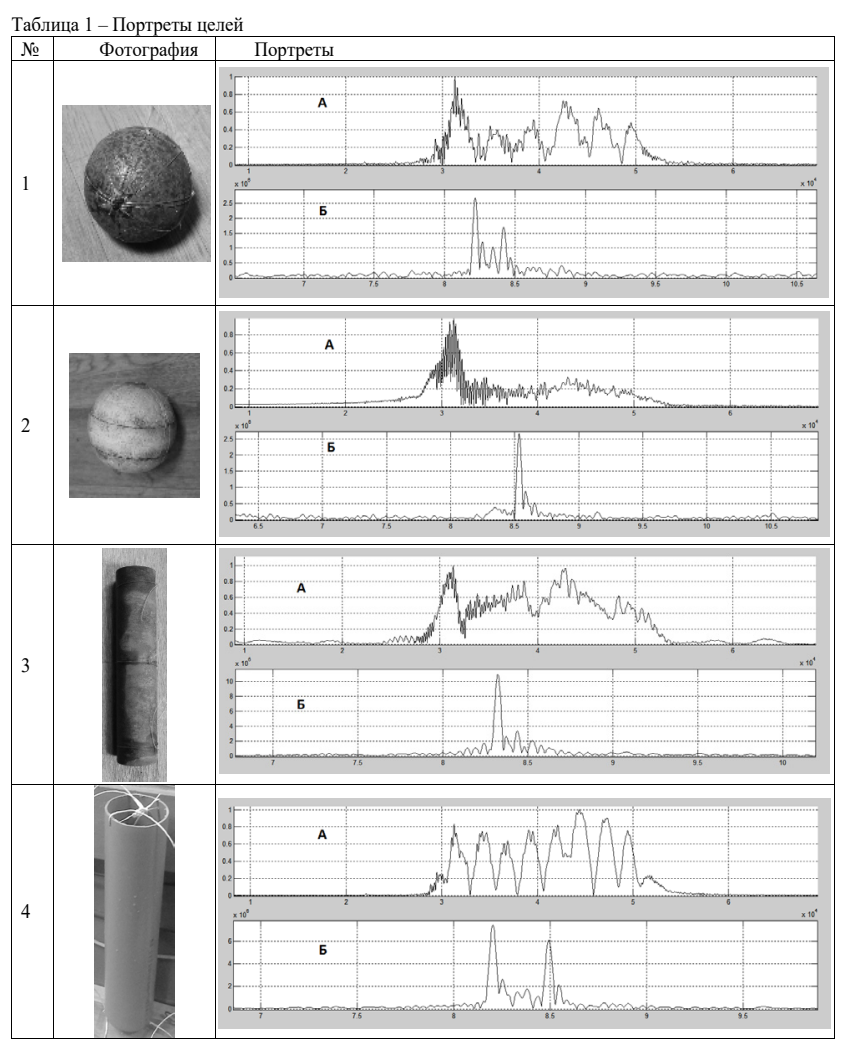


the formation of secondary echoes with differing time delays [9].

All this indicates the effectiveness of using ultrawideband probing signals in active SSV as compared to narrowband signals.

\section{CONCLUSION}

Thus, the results show the possibility of obtaining high resolution at low frequencies and additional classification features when using UWB signals in active sonar systems. These properties of UWB signals can be used to solve the problem of recognition and classification of underwater objects.

\section{REFERENCES}

1. Demidov AI, Komochkov RS, Mosolov SS, Sknarya AV, Tutynin EV. Otechestvennye gidrolokatory so slozhnymi signalami proizvodstva OAO «NIIP». Trudy 10th V seross. konf. "Prikladnye tekhnologii gidroakustiki $i$ gidrofiziki", St. Petersburg, 2010, p. 152-154.

2. Evtyutov AP, Lyalikov AP, Kolesnikov AE, Korepin EA. Spravochnik po gidroakustike. Leningrad, Sudostroenie Publ., 1988, 552 c.

3. Астанин $\Lambda$, Kostylev АA. Osnovy sverhshirokopolosnyh radiolokacionnyh izmereniy [Fundamentals of ultra-wideband radar measurements]. Moscow, Radio i svyaz Publ., 1989, 192 p.

4. Lew H. Broadband Active Sonar: Implications and Constraints. Technical Report No. DSTOTR-0435, Melbourne, Australia, 1996.

5. Capus C, Pailhas Y, Brown K, Evans J. Underwater detection, classification and tracking using wideband sonar. Proc. 3rd Intern. Conf. and Exbibition on Underwater Acoustic Measurements, Nafplio, Greece, 2009.

6. Zalogin NN, Sknarya AB. Selection of sounding signal for sonar. Proc. 13th Intern. Conf. "Radiolocation, navigation, communication", Voronezh, 2007, p. 2722-2730.

7. Demidov AI, Komochkov RS, Sknarya AV, Toshchov SA. O perspektivah ispol'zovaniya v gidrolokacii sverhshirokopolosnyh zondiruyushchih signalov [On the prospects of using ultra-wideband probing signals in sonar]. Iqvestiya YUFU, 2013, 9:90-96.

8. Sknarya AB, Toshchov SA. K voprosu o preimushchestve ispol'zovaniya sverhshirokopolosnyh signalov pri reshenii zadachi raspoznavaniya celej $\mathrm{v}$ gidrolokacii [On the issue of the advantage of using ultrawideband signals when solving the problem of target recognition in sonar]. Trudy 4th vseross. nauchn. konf. "Sverbshirokopolosnye signaly $v$ radiolokacii, syyazi $i$ akustike", Murom, 2013, p. 66-69.

9. Shenderov EL. Izluchenie $i$ rasseyanie qunka [Radiation and scattering of sound]. Leningrad, Sudostroenie Publ., 1989, 304 p. 